ORIGINAL ARTICLE

PRACA ORYGINALNA

\title{
REGULATION OF MICRORNA EXPRESSION LEVEL BY CHOLERETIC THERAPY IN FUNCTIONAL DISORDERS OF THE GALLBLADDER AND ODDI'S SPHINCTER IN CHILDREN
}

D0I: 10.36740/WLek202001107

\author{
Alexandr E. Abaturov' ${ }^{1}$, Iryna L. Vysochyna ${ }^{1}$, Veronika L. Babych', Victor E. Dosenko ${ }^{2}$ \\ 'STATE INSTITUTION «DNIPROPETROVSK MEDICAL ACADEMY OF THE MINISTRY OF HEALTH OF UKRAINE», DNIPRO, UKRAINE \\ ${ }^{2}$ BOGOMOLETS INSTITUTE OF PHYSIOLOGY OF THE NATIONAL ACADEMY OF SCIENCES OF UKRAINE, KYIV, UKRAINE
}

\begin{abstract}
The alm: To study the effect of choleretic therapy on the level of microRNA expression in functional disorders of the gallbladder and Oddi's sphincter in children.

Materials and methods: Fifty patients with functional disorders of the gallbladder and Oddi's sphincter who received standard therapy in combination with ursodeoxycholic acid, 20 patients - standard therapy without ursodeoxycholic acid, and 20 healthy children were examined. The level of expression of microRNA-378f, microRNA-4311, microRNA-4714$3 p$ in the blood serum by the method of real-time polymerase chain reaction with reverse transcription according to the protocol TaqMan Gene Expression Assays was performed. Results: It was demonstrated that the activity profile of microRNA-4714-3p was significantly lower in those examined with functional disorders of the gallbladder and 0ddi's sphincter than in practically healthy children $(\mathrm{p}<0.05)$. After standard therapy combined with ursodeoxycholic acid in children with functional disorders of the gallbladder and Oddi's sphincter, the level of expression of microRNA-378f is significantly higher than before therapy $(5.23 \pm 0.70 \mathrm{SU}$ and $2.02 \pm 0.57 \mathrm{SU}$ respectively) ( $p<0.05)$. Against the background of standard therapy with the addition of ursodeoxycholic acid or without it, the expression profile of microRNA-4714-3p in the blood serum in children with functional disorders of the gallbladder and Oddi's sphincter significantly decreased (1.93 $\pm 0.58 \mathrm{SU}$ and $1,14 \pm 0,53 \mathrm{SU}$ respectively) $(p<0.05)$.

Conclusions: Ursodeoxycholic acid in children with functional disorders of the gallbladder and Oddi's sphincter affects the activity of generation of gene regulators of the cellular mechanisms of microRNA-378f and microRNA-4714-3p.
\end{abstract}

KEY WORDS: The functional disorders of the gallbladder and Oddi's sphincter, microRNA, ursodeoxycholic acid, children

Wiad Lek. 2020;73(1):41-45

\section{INTRODUCTION}

Scientific and practical studies of recent years indicate the wide prevalence of functional gastrointestinal disorders, as one of the most pressing problems of modern pediatric gastroenterology [1].

Functional disorders of the gallbladder and Oddi's sphincter are put down to functional disorders of the biliary system in children according to the Rome IV consensus the functional gastrointestinal disorders (2016) [1]. The acuteness of the problem of functional disorders of the gallbladder and Oddi's sphincter in Pediatric Gastroenterology is stipulated by the high prevalence and the possibility of transition to biliary system's organic pathology $[2 ; 3]$. The functioning of the gallbladder and Oddis sphincteris is carried out due to the humoral effect of secretin, cholecystokinin [4]. Regulation of the production of these substances is performed by microRNA [5]. MicroRNA (miRNA, miR) are small non - coding RNA molecules of 21-23 nucleotides that regulate gene expression at the post-transcription level by RNA interference and indirectly they participate in protein synthesis, cell differentiation, and tissue [6].

In recent years, there is evidence of association of amplification or inhibition of microRNA generation with dysfunction and development of the biliary system's diseases $[5 ; 7 ; 8]$.
Ursodeoxycholic acid (UDCA) is a tertiary bile acid that is formed in hepatocytes and intestinal cells. Ursodeoxycholic acid has hepatoprotective, anti-cholestatic, litholytic cytoprotective, antifibrotic, anti-apoptotic, antioxidant, immunomodulating effects. The results of numerous scientific studies confirm the positive therapeutic effect of ursodeoxycholic acid preparations in diseases of the digestive system $[9 ; 10]$. Recently, scientists have paid considerable attention to determining the effect of UDCA on the expression of various microRNAs $[8 ; 11 ; 12]$. However, the effect of ursodeoxycholic acid on the expression profile of microRNA in functional disorders of the gallbladder and Oddi's sphincter in children has not been determined yet.

\section{THE AIM}

Objective: to study the effect of choleretic therapy on the level of microRNA expression in functional disorders of the gallbladder and Oddi's sphincter in children.

\section{MATERIALS AND METHODS}

The comprehensive survey of 90 children aged 4 to 14 years was conducted according to the Rome IV consensus 
the functional gastrointestinal disorders (2016) on the basis of the municipal institution "Dnipro city clinical hospital №1” Dnipro city Council, Dnipro city, Ukraine. 70 patients showed clinical signs of functional disorders of the gallbladder and Oddi's sphincter [1]. Verification of diagnosis and provision of medical care to patients were carried out in accordance with the order of the Ministry of Health of Ukraine dated 29.01.2013 № 59 “On approval of unified clinical protocols of medical care for children with diseases of the digestive system" [3]. The research was conducted in accordance with the principles of the Helsinki Declaration and with the informed consent of the patient's parents or guardians.

Patients with functional disorders of the gallbladder and Oddi's sphincter by simple randomization were divided into two groups. The first (1st, main) group was represented by 50 patients with functional disorders of the gallbladder and Oddi's sphincter. They received standard therapy in accordance with the provisions of the order of the Ministry of Health of Ukraine dated 29.01.2013 №59 in combination with ursodeoxycholic acid, which was prescribed at the rate of $10-15 \mathrm{mg} / \mathrm{kg} /$ day. The second (2nd) group (comparison group) included 20 patients with functional disorders of the gallbladder and Oddi's sphincter. They received standard therapy in accordance with the provisions of the order of the Ministry of Health of Ukraine dated 29.01.2013. № 59 without ursodeoxycholic acid. The course of treatment was 4 weeks. The effectiveness of treatment after completion of complex therapy for all children was evaluated. The third (3rd) group (control group) included 20 healthy children. Before treatment and after treatment, the molecular genetic study was conducted to determine the level of expression of microRNA-378f, microRNA-4311, microRNA-4714-3p in blood serum by real-time polymerase chain reaction with reverse transcription in children of groups 1 and 2 and once in children of group 3. It was performed according to the Taq Man Gene Expression Assays Protocol in the certified laboratory of the Department of General and molecular Pathophysiology of the Institute of Physiology after A. A. Bogomolets of NAS of Ukraine (Head - Doctor of Medical Science, Professor A. A. Krishtal). The study included the following steps: isolation of total RNA from the primary material (blood serum); isolation of DNA from the primary material (blood serum); reverse transcription; polymerase chain reaction (PCR); restriction analysis; polymerase-chain reaction in real time; calculation of the number of amphilic molecules and construction of the calibration curve.

Statistical analysis of the results was carried out using the program “STATISTICA 6.1” (№ AGAR909E415822FA). Depending on the test results, parametric and nonparametric methods of statistics were used. Differences between the signs were considered statistically significant at $\mathrm{p}<0.05$.

\section{RESULTS}

The average age of children who received standard therapy in combination with ursodeoxycholic acid was $7.84 \pm 0.39$ years, without ursodeoxycholic acid $-8.90 \pm 0.52$ years, practically healthy children $-8.15 \pm 0.60$ years $(p>0.05)$. No statistically significant differences were found in the study groups by age and gender $(\mathrm{p}>0.05)$. In the majority of the examined children $(57.1 \%)$, clinical signs of functional disorders of the gallbladder and Oddi's sphincter were repeated. The duration of the disease in patients of the first and second groups ranged from 1 to 5 years.

During the study, family aggregation of biliary tract pathology in children's pedigrees with functional disorders of the gallbladder and Oddi's sphincter was determined. The burdened hereditary history of functional disorders of the gallbladder and Oddi's sphincter, chronic cholecystitis and cholelithiasis was found in 63 children (90\%) of the first and second groups of the study.

Contributing factors to the onset or exacerbation of the disease in patients with functional disorders of the gallbladder and Oddi's sphincter were eating disorders (in 36 (72\%) children of the main group and in $16(80 \%)$ patients of the comparison group), psychoemotional load (25 (50\%) and 8 (40\%), respectively), hypodynamic lifestyle (15 (30\%) and $25(50 \%)$, respectively) and the presence of foci of chronic infection (7 (14\%) and $4(20 \%)$, respectively) ( $\mathrm{p}>0.05)$.

All patients of both groups of observation were admitted to the hospital with manifestations of abdominal pain, dyspeptic and asthenovegetative syndromes of different duration and severity. 28 (56\%) children of the first group and $13(65 \%)$ patients of the second group complained of recurrent pain in the epigastrium and right hypochondrium, $13(26 \%)$ children of the 1st group and $3(15 \%)$ examined 2nd group - for recurrent pain in the umbilical region, 9 (18\%) patients of the main group and $4(20 \%)$ children of the comparison group - for pain in the right hypochondrium at the beginning of the observation $(\mathrm{p}>0.05)$. Pain was observed in the right hypochondrium in $42(84 \%)$ children of the first group and in 18 (90\%) patients of the second group on palpation of the abdomen ( $>0.05)$. Dyspeptic symptoms were presented with nausea $(22(44 \%)$ patients of the main group and 8 (40\%) of the comparison group), loss of appetite $(26(52 \%)$ and $9(45 \%)$ respectively), belching bitter (11 $(22 \%)$ and $4(20 \%)$, respectively) before treatment ( $>0.05$ ). $34(68 \%)$ patients of the 1st group and $14(70 \%)$ children of the 2 nd group had increased fatigue, decreased performance, and general weakness before treatment $(\mathrm{p}>0.05)$.

Significant differences in the regression of the main symptoms of abdominal pain, dyspeptic and astenovegetative syndromes in children of the main group and the comparison group were established after the treatment. Thus, symptoms of pain remained after treatment in 7 (14\%) children of the first group and in $8(40 \%)$ patients of the second group $(\mathrm{p}<0.05)$. All children of the main group after treatment with UDCA disappeared signs of dyspeptic syndrome. In 3 (15\%) patients of the comparison group, after treatment without UDCA, complaints of nausea and decreased appetite persisted. In $9(18 \%)$ patients of the 1 st group and in 11 (55\%) children of the 2 nd group symptoms of the asthenovegetative syndrome were observed after the treatment $(\mathrm{p}<0.05)$. 
Table 1. Results of the biochemical studies of blood serum in children with functional disorders of the gallbladder and Oddi's sphincter before and after treatment $(\mathrm{M} \pm \mathrm{m})$

\begin{tabular}{|c|c|c|c|c|}
\hline \multirow{2}{*}{\multicolumn{2}{|c|}{ Children's group }} & \multicolumn{3}{|c|}{ Blood biochemical parameters } \\
\hline & & \multirow{2}{*}{$\begin{array}{c}\text { Alkaline phosphatase, } \mathbf{n} / \mathbf{l} \\
507,92 \pm 19,94 *\end{array}$} & \multirow{2}{*}{$\begin{array}{c}\text { Aspartate aminotransferase, } \mathbf{n} / \mathbf{I} \\
34,96 \pm 1,31 *\end{array}$} & \multirow{2}{*}{$\begin{array}{c}\text { Alanine aminotransferase, } \mathbf{n} / \mathbf{l} \\
18,76 \pm 0,91 *\end{array}$} \\
\hline Children who & $\begin{array}{c}\text { Before } \\
\text { treatment }\end{array}$ & & & \\
\hline$(n=50)$ & $\begin{array}{c}\text { After } \\
\text { treatment }\end{array}$ & $359,53 \pm 16,59 * * *$ & $26,18 \pm 0,97 * *$ & $14,96 \pm 0,64 * *$ \\
\hline \multirow{2}{*}{$\begin{array}{l}\text { Children who did } \\
\text { not receive UDCA } \\
\qquad(n=20)\end{array}$} & $\begin{array}{c}\text { Before } \\
\text { treatment }\end{array}$ & $542,85 \pm 40,95 *$ & $28,20 \pm 1,31 *$ & $17,35 \pm 1,52$ \\
\hline & $\begin{array}{c}\text { After } \\
\text { treatment }\end{array}$ & $499,50 \pm 40,16 *$ & $29,65 \pm 1,66 *$ & $15,90 \pm 1,22$ \\
\hline \multicolumn{2}{|c|}{ Practically healthy children $(n=20)$} & $202,95 \pm 9,07$ & $24,20 \pm 0,89$ & $14,50 \pm 0,57$ \\
\hline
\end{tabular}

Notes: ${ }^{*}-p<0.05-$ significantly compared with the parameter value in healthy children;

** $-p<0.05-$ significantly compared with the parameter value before treatmen.

Table 2. Results of the study of level serum expression of microRNA in children with functional disorders of the gallbladder and Oddi's sphincter before and after treatment $(M \pm m)$

\begin{tabular}{|c|c|c|c|c|}
\hline \multirow{2}{*}{\multicolumn{2}{|c|}{ Children's group }} & \multicolumn{3}{|c|}{ Level expression of microRNA } \\
\hline & & MicroRNA-378f, SU & MicroRNA-4311, SU & Micro-RNA-4714-3p, SU \\
\hline \multirow{2}{*}{$\begin{array}{l}\text { Children who received } \\
\text { UDCA }(n=50)\end{array}$} & $\begin{array}{c}\text { Before } \\
\text { treatment }\end{array}$ & $2,02 \pm 0,57$ & $1,48 \pm 0,35$ & $5,56 \pm 1,50^{*}$ \\
\hline & $\begin{array}{c}\text { After } \\
\text { treatment }\end{array}$ & $5,23 \pm 0,70 * *$ & $1,17 \pm 0,18$ & $1,93 \pm 0,58 * * *$ \\
\hline \multirow{2}{*}{$\begin{array}{l}\text { Children who did not } \\
\text { receive UDCA }(n=20)\end{array}$} & $\begin{array}{c}\text { Before } \\
\text { treatment }\end{array}$ & $2,08 \pm 0,96$ & $1,58 \pm 0,47$ & $4,66 \pm 1,57^{*}$ \\
\hline & $\begin{array}{c}\text { After } \\
\text { treatment }\end{array}$ & $4,49 \pm 0,79$ & $1,85 \pm 0,88$ & $1,14 \pm 0,53^{* * *}$ \\
\hline \multicolumn{2}{|c|}{ Practically healthy children $(n=20)$} & $5,05 \pm 2,85$ & $3,07 \pm 1,41$ & $53,62 \pm 10,42$ \\
\hline
\end{tabular}

Notes: ${ }^{*}-p<0.05-$ significantly compared with the parameter value in healthy children;

** $-p<0.05-$ significantly compared with the parameter value before treatmen.

The cholestasis markers of the biochemical hepatogram (alkaline phosphatase, aspartate aminotransferase, alanine aminotransferase) in patients with functional disorders of the gallbladder and Oddi's sphincter before treatment were significantly higher than those in healthy children ( $\mathrm{p}>0.05)$ (table 1).

A significant decrease in the levels of alkaline phosphatase, aspartate aminotransferase, alanine aminotransferase in children with functional disorders of the gallbladder and Oddi's sphincter was found when analyzing the dynamics of biochemical hepatogram indicators after complex therapy using ursodeoxycholic acid. In children, who did not receive UDCA therapy, the above indicators did not have significant changes.

A significant decrease in the dynamic contractility of the gallbladder found in patients with functional disorders of the gallbladder and Oddi's sphincter both groups when studying the data of transabdominal dynamic ultrasound before therapy. The contractility of the gallbladder was $23.44 \pm 1.56 \%$ in children of the 1 st group before treatment and $23.75 \pm 2.29 \%$ in children of the 2 nd group ( $>0.05$ ). The indicators of both groups were significantly lower than in practically healthy children $-49.55 \pm 1.11 \%(\mathrm{p}<0.05)$.
The contractility of the gallbladder significantly increased to $45.56 \pm 1.68 \%$ compared in patients of the first group with the pre-treatment index $(\mathrm{p}<0.05)$. The contractility of the gallbladder averaged $29.69 \pm 2.99 \%$ in children of the second group after treatment without UDCA and did not have a significant difference from the indicator before therapy $(\mathrm{p}>0.05)$.

The results of molecular genetic studies of serum expression of micro-RNA before and after treatment in children with functional disorders of the gallbladder and Oddi's sphincter and in healthy children are presented in table 2 .

It was found that the parameters of the main group and the comparison group did not differ statistically significantly ( $p>0.05)$ during studying of the level of expression of microRNA-378f, microRNA-4311, microRNA-4714-3p in serum before treatment in children with functional disorders of the gallbladder and Oddi's sphincter.

It was determined that the activity profile of microRNA-4714-3p in the examined groups 1st and 2nd with functional disorders of the gallbladder and Oddi's sphincter was significantly lower than in healthy children in the anal$y$ sis of the results of molecular genetic research $(p<0.05)$.

However, there was no statistically significant difference 
with the indicators in practically healthy children in the study of the level of expression of microRNA-378f and microRNA-4311 in children with functional disorders of the gallbladder and Oddi's sphincter before treatment ( $\mathrm{p}>0.05)$.

Correlation analysis showed that the level of expression of microRNA-4714-3p in serum before therapy in the examined children positively correlated with a decrease in the contractile function of the gallbladder according to ultrasound examination $(\mathrm{r}=+0.36 ; \mathrm{p}<0,05)$.

During the investigation it was established that the dynamics of the activity profiles of microRNA-378f and microRNA-4714-3p differed significantly after the therapy (table 1). After standard therapy in combination with ursodeoxycholic acid in children with functional disorders of the gallbladder and Oddi's sphincter, the level of expression of microRNA-378f approached the value of $5.23 \pm 0.70$ $\mathrm{SU}$, which was significantly higher than before therapy in children of this group $(p<0.05)$. At the same time, after standard therapy alone without ursodeoxycholic acid, the level of microRNA-378f expression in children of the comparison group did not differ significantly from the pre-treatment index ( $>0.05)$.

Against the background of standard therapy with the addition of ursodeoxycholic acid and without it, the expression profile of microRNA-4714-3p in serum of children with functional disorders of the gallbladder and Oddi's sphincter of the 1st and 2nd groups significantly decreased to the level of $1.93 \pm 0.58 \mathrm{SU}$ and $1.14 \pm 0.53 \mathrm{SU}$ respectively $(\mathrm{p}<0.05)$.

\section{DISCUSSION}

When studying the results of the study, positive clinical dynamics of manifestations of functional disorders of the gallbladder and Oddi's sphincter was determined after complex therapy with the use of ursodeoxycholic acid. This fact can be explained by an improvement in the rheological properties of bile and a decrease in the concentration of primary and secondary bile acids under the influence of ursodeoxycholic acid.

As a result of the study, it was found that at the beginning of observation of patients with functional disorders of the gallbladder and Oddi's sphincter, the average levels of expression of microRNA-378f, microRNA-4311, microRNA-4714-3p in serum of children of the main group and the comparison group were identical. It can be assumed that the significant decrease in the expression profile of microRNA-4714-3p before treatment in children of both groups was associated with the decrease in the contractile function of the gallbladder in children with functional disorders of the gallbladder and Oddi's sphincter.

Analysis of the study data showed that after complex therapy with and without ursodeoxycholic acid in children with functional disorders of the gallbladder and Oddi's sphincter, the dynamics of levels of expression of microRNA-378f and microRNA-4714-3p differed significantly. Probably, the significant increase in the expression profile of microRNA-378f, which was observed after the course of treatment with ursodeoxycholic acid, contributed to the restoration of bile drainage. It is possible that the decrease in the expression of microRNA4714-3p, which was observed after the course of treatment regardless of the use of ursodeoxycholic acid, may be due to modification of the diet.

\section{CONCLUSIONS}

1. As the result of studies it was found that in children with functional disorders of the gallbladder and Oddi's sphincter, changes in the profile of micro-RNA expression are observed.

2. These molecular genetic studies indicate the unique property of ursodeoxycholic acid in children with functional disorders of the gallbladder and Oddi's sphincter to influence the activity of the generation of gene regulators of cellular mechanisms of microRNA-378f and microRNA-4714-3p.

3. The use of ursodeoxycholic acid in the treatment of functional disorders of the gallbladder and Oddi's sphincter in children is justified due to its high efficiency.

\section{REFERENCES}

1. Drossman D.A. Functional Gastrointestinal Disorders: History, Pathophysiology, Clinical Features, and Rome IV. Gastroenterology. May 2016; 6 (150): 1262-1279.e2. doi:10.1053/j.gastro.2016.02.032.

2. Volosovec OP, Zubarenko OV, Kryvopustov SP ta in. Pediatrics (Gastroenterology and Pathology of the Early Age): Teach. Manual. Odessa: Printing house, Printing South. 2017:165-180. (Ukrainian).

3. Unified clinical protocol of medical aid for children with diseases of the digestive system: Order of the Ministry of Health of Ukraine № 59 dated January 29, 2013. Modern Pediatrics. 2013;4:20-31. (Ukrainian).

4. Liddle RA. Regulation of cholecystokinin synthesis and secretion in rat intestine. J Nutr. 1994; 124(48): 1308S-1314S. PMID:8064378.

5. Otsuka M, Kishikawa T, Yoshikawa T, Yamagami M, Ohno M, Takata A, Shibata $C$ at al. MicroRNAs and liver disease. J Hum Genet. 2016 May 26. doi:10.1038/jhg.2016.53.

6. Statistics about the current Human GENCODE Release: version 27 (January 2017 freeze, GRCh38 - Ensembl 90). Available at: https// www.gencodegenes. org/stats/current.html. Accessed: August, 2017.

7. Abaturov $0 \mathrm{E}$, Babich VL. The role of microRNA in diseases of the biliary system. Child's Health. 2017; 7(12): 155-161. doi: 10.22141/22240551.12.7.2017.116191. (Ukrainian).

8. Sakamoto T, Morishita A, Nomura T, Tani J, Miyoshi H at al. Identification of microRNA profiles associated with refractory primary biliary cirrhosis. Mol. Med. Rep. - 20160ct; 14(4):3350-6. doi:10.3892/mmr.2016.5606.

9. Babich VL. Application of ursodeoxycholic acid in the treatment of functional disorders of the biliary system. Modern medical technology. 2017; 3(34): 64-70. (Ukrainian).

10. Tabibian JH, Lindor KD. Ursodeoxycholic Acid Treatment in Primary Sclerosing Cholangitis. Primary Sclerosing Cholangitis. 2017. doi:10.1007/978-3-319-40908-5_11.

11. Katsushima F, Takahashi A, Sakamoto N, Kanno Y, Abe K, Ohira H. Expression of micro-RNAs in peripheral blood mononuclear cells from primary biliary cirrhosis patients. Hepatology Research. 2014; 44 (10): E189-E197. DOI: 10.1111/hepr.12198. 
12. Rodrigues PM, Afonso MB, Simão AL. miR-21 ablation and obeticholic acid ameliorate nonalcoholic steatohepatitis in mice. Cell Death Dis. 2017; 8(4): e2748. doi: 10.1038/cddis.2017.172.

\section{ORCID and contributionship:}

Alexandr E. Abaturov - 0000-0001-6291-5386 A,C,D,E,F

Iryna L. Vysochyna - 0000-0003-3532-5035 B,D,E,F

Veronika L. Babych - 0000-0001-9261-9051 B,C,D,E,F

Victor E. Dosenko - 0000-0002-6919-7724 B,C,E,F

\section{Conflict of interest:}

The Authors declare no conflict of interest

\section{CORRESPONDING AUTHOR}

Veronika L. Babych

Department of Pediatrics 1 and Medical Genetics

State Institution "Dnipropetrovsk Medical Academy

of the Ministry of Health of Ukraine"

Street 9, V. Vernadskogo, 49044, Dnipro, Ukraine

e-mail: babich.veronica84@gmail.com

Received: 21.04.2019

Accepted: 05.11.2019

A - Work concept and design, B - Data collection and analysis, C - Responsibility for statistical analysis,

D - Writing the article, $\mathbf{E}$-Critical review, $\mathbf{F}$ - Final approval of the article 